\title{
Invasive pneumococcal diseases among hospitalized children in Lima, Peru
}

\author{
Theresa J. Ochoa, ${ }^{1-3}$ Martha Egoavil, ${ }^{1,3}$ María E. Castillo, ${ }^{1,3,4}$ \\ Isabel Reyes, ${ }^{3,5}$ Eduardo Chaparro, ${ }^{1,3,6}$ Wilda Silva, ${ }^{3,7}$ \\ Francisco Campos, ${ }^{3,8}$ and Andrés Sáenz ${ }^{3,9}$
}

Suggested citation Ochoa TJ, Egoavil M, Castillo ME, Reyes I, Chaparro E, Silva W, et al. Invasive pneumococcal diseases among hospitalized children in Lima, Peru. Rev Panam Salud Publica. 2010;28(2):121-7.

ABSTRACT Objective. To determine the epidemiology of invasive pneumococcal disease (IPD) and the antibiotic susceptibility and serotype distribution of S. pneumoniae in pediatric patients in Lima, Peru.

Methods. A 2-year, multicenter, passive surveillance study conducted from May 2006April 2008 in 11 public hospitals and five private laboratories in Lima, Peru, in patients less than 16 years of age with sterile site cultures yielding S. pneumoniae. Antibiotic susceptibility was performed by Etest ${ }^{\circledR}$ (AB Biodisk, Solna, Switzerland). Strains were serotyped by the Quellung reaction.

Results. In all, 101 IPD episodes were studied, $68.3 \%$ of which were among children less than 24 months of age. Diagnoses were: pneumonia (47.5\%), meningitis (38.6\%), and sepsis (7.9\%). The overall case fatality rate was $22.0 \%$; case fatality rate in meningitis was $32.4 \%$. While $80.0 \%$ of fatal cases were in those less than 24 months of age, only 50.7\% of non-fatal cases $(\mathrm{P}<0.05)$ were in this age group. Resistance rates were high for trimethoprim/ sulfamethoxazole $(76.2 \%)$, erythromycin $(24.8 \%)$, and penicillin $(22.8 \%)$. The most common serotypes were $14,6 B, 19 F, 23 F$, and 5 , which accounted for $69.7 \%$ of all strains and $87.0 \%$ of penicillin non-susceptible strains.

Conclusion. IPD in hospitalized children in Lima is associated with high antimicrobial resistance levels and elevated case fatality rate, especially in young children. This baseline data will be useful for evaluating the effects of vaccine introduction.

Key words Streptococcus pneumoniae; pneumococcal infections; child, hospitalized; child care; pneumococcal vaccines; Peru.

Streptococcus pneumoniae is a major cause of morbidity and mortality world-

\footnotetext{
1 Universidad Peruana Cayetano Heredia, Lima, Peru. Send correspondence to Theresa J. Ochoa, theresa j.ochoa@uth.tmc.edu.

2 University of Texas School of Public Health, Houston, Texas, United States of America.

3 Grupo Peruano de Investigación en Neumococo (GPIN), Lima, Peru.

4 Instituto Nacional de Salud del Niño, Lima, Peru.

5 Hospital de Emergencias Pediátricas, Lima; Peru.

6 Hospital Nacional Cayetano Heredia, Lima, Peru.

7 Hospital Edgardo Rebagliati, Lima, Peru.

8 Hospital Nacional Docente Madre-Niño San Bartolomé, Lima, Peru.

9 Hospital Daniel A. Carrión, Lima, Peru.
}

wide, particularly in young children, the elderly, patients with chronic diseases, and immunocompromised individuals of all ages. Globally, approximately 1.6 million deaths due to pneumococcal pneumonia and meningitis are believed to occur among young children every year, mostly in developing countries (1). In Latin America, it has been estimated that two children die every hour due to pneumococcus (2).

Antibiotic-resistant S. pneumoniae is a clinical and public health problem around the world. Levels of penicillin resistance vary geographically. In Latin America, penicillin resistance is found in approximately $30 \%$ of isolates, with important variations among countries $(3,4)$; however, the data for this geographic area needs to be re-evaluated with the new penicillin resistance breakpoints for pneumonia, so that appropriate guidelines for treatment can be established for Latin America.

Globally, S. pneumoniae is one of the leading causes of vaccine-preventable death in children less than 5 years of age. The new pneumococcal conjugated vac- 
cines are highly effective in reducing the pneumococcal disease rates in young children and reducing the rates of disease due to resistant strains (5-9). However, there are important geographical differences in invasive pneumococcal disease (IPD) rates and serotype frequency in young children around the globe (10-13).

In areas of the world were the conjugated vaccine is being introduced in the general population (e.g., Peru), it is important to determine the burden of pneumococcal diseases in order to develop effective country-specific vaccine strategies, and implement strong sustained surveillance to monitor the effect of vaccination (14). Because there is no data available on the burden of pneumococcal diseases in Peru, a passive surveillance study was conducted to determine the epidemiology of IPD, the disease severity, the antibiotic susceptibility, and serotype distribution of S. pneumoniae in pediatric patients in Lima, Peru.

\section{MATERIALS AND METHODS}

\section{Study design}

This was a 2-year prospective, passive, multicenter surveillance study of IPD in 11 public hospitals and five private clinical laboratories in Lima. Of the 11 hospitals, eight were Ministry of Health (MINSA) institutions: Instituto Nacional de Salud del Niño, Hospital de Emergencias Pediátricas, Hospital Nacional Cayetano Heredia, Hospital Nacional Docente Madre-Niño San Bartolomé, Hospital Daniel A. Carrión, Hospital María Auxiliadora, Hospital Hipólito Unanue, Hospital Arzobispo Loayza; and three were Social Security (EsSalud) institutions: Hospital Edgardo Rebagliati, Hospital Guillermo Almenara, and Hospital Sabogal. The five private laboratories were: Blufstein, MedLab, AngloLab, Roe, and Suiza Lab.

This was a passive surveillance study in that only cultures for S. pneumoniae were collected. An active surveillance study was not conducted, i.e., additional cultures for suspected cases of invasive disease were not performed. Cultures had been ordered by the attending physicians based on clinical judgment and the hospital's protocol. The study was approved by the Institutional Review Board of the Universidad Peruana Cayetano Heredia (Lima, Peru) and by each participating hospital's board.

\section{Case definition}

Invasive pneumococcal disease cases were defined by isolation of S. pneumoniae from a normally sterile site (blood, cerebral spinal fluid [CSF], pleural fluid, joint fluid, or peritoneal fluid) from patients less than 16 years of age, admitted by the participating hospitals. S. pneumoniae isolates from non-sterile sites (nasopharynx, pharynx, tonsils, or sputum) were excluded. Clinical and epidemiological data were obtained from the medical charts. The diagnosis of pneumonia, meningitis, sepsis, and other diagnosis were clinical definitions taken from medical records. Pneumococcal pneumonia was defined by a positive blood or pleural fluid culture in the presence of an infectious process with fever and respiratory distress and evidence of pulmonary infiltrates on the chest X-ray. Pneumococcal meningitis was defined by a positive CSF or blood culture in the presence of an infectious process with fever, and signs and symptoms of neurological involvement and an abnormal CSF. Pneumococcal sepsis was defined by a positive blood culture in the presence of a systemic inflammatory response syndrome (SIRS).

\section{Incidence rate determination}

Since the Ministry of Health did not have exact data on the populations served by each hospital in each district of the Province of Lima, the IPD rate was determined using an estimate based on each district's population and the number of hospitals and clinics available. Accordingly, it was determined that an estimated $75 \%$ of the total pediatric population is served by the study's participating hospitals and clinics. The mean annual IPD rate (number of cases / 100000 children) was calculated based on rates in the study's first and second years among children $<2$ years of age (1 month-24 months of age) and $<5$ years of age (1 month-60 months of age). The population of each district within the Province of Lima was obtained from the Ministry of Health of Peru (June 2008 projected population).

\section{Laboratory studies}

S. pneumoniae isolates were transported, in the blood agar plate, from each hospital to a central laboratory on the day of isolation. S. pneumoniae identification was confirmed by conventional methods based on the colony morphology, alpha hemolysis, Gram stain, bile solubility, and optochin susceptibility. Antimicrobial susceptibility to five antibiotics-ceftriaxone, chloramphenicol, erythromycin, penicillin, and trimethoprim/sulfamethoxazole [TMP/SMX]was determined by minimal inhibitory concentration (MIC) using Etest $^{\circledR}$ (AB Biodisk, Solna, Sweden). Susceptibility was assessed according to the new 2008 performance standards of the Clinical and Laboratory Standards Institute (CLSI/NCCLS) (15). The penicillinparenteral MIC $(\mathrm{mcg} / \mathrm{mL})$ breakpoints for non-meningeal isolates used were: $\leq 2$ susceptible, 4 intermediate, and $\geq 8$ resistant; the penicillin-parenteral MIC breakpoints for meningeal isolates were $\leq 0.06$ susceptible and $\geq 0.12$ resistant. The strains with high and intermediate resistance were considered non-susceptible for the analysis. Serotyping was performed in a reference lab (Soroka University Medical Center, Beer-Sheva, Israel) by capsular swelling observed microscopically (Quellung reaction) after suspension in type-specific antisera.

\section{Statistical analysis}

This is a descriptive study; the data is presented as number of cases and percentages. Comparisons were done using Chi square with Yates correction, Student $\mathrm{t}$-test, and non-parametric test according to the variables evaluated.

\section{RESULTS}

The study was conducted in the city of Lima, which has a population of 7443766 , including 249799 children less than 24 months of age, and 773280 children less than 60 months of age. The estimated, mean annual rate of IPD in children less than 24 months of age was 18.4/100 000 $(17.1 / 100000$ in the first year of the study, and 19.8/100000 in the second year). The estimated mean annual rate of IPD in children younger than 60 months of age was 7.7/100000 (7.1/100000 in the first year of the study, and 8.3/ 100000 in the second year).

In May 2006-April 2008, 101 invasive pneumococcal disease episodes from 97 patients were studied (4 patients had 2 separate episodes of IPD). Patient age ranged from 1 month-15.8 years, with a 
median of 1.2 years; $68.3 \%$ of episodes were in children $<2$ years of age (Table 1). The main diagnoses were pneumonia and meningitis. More than one-third of all patients had an underlying illness, had been previously hospitalized, and had received antibiotics in the prior 3 months. Only $8.6 \%(6 / 70)$ of patients attended daycare. None of the children had been vaccinated with the heptavalent conjugated pneumococcal vaccine or the 23-valent vaccine. All samples were collected prior to the introduction of the heptavalent conjugated vaccine (PCV-7) in the National Immunization Program in Peru.

Followup data was available for 91 patients: $59(64.8 \%)$ were discharged in good condition; 7 (7.6\%) had minor general sequelae; $5(5.5 \%)$ had severe neurological sequelae; and $20(22.0 \%)$ died. The case fatality rate was $16.3 \%$ (7/43) for pneumonia; $25.0 \%$ (2/8) for sepsis; and $32.3 \%(11 / 34)$ for meningitis. The overall case fatality rate was $22.0 \%$ $(22 / 91) ; 80.0 \%$ of fatal cases were in those less than 24 months of age versus $50.7 \%$ of non-fatal cases $(P<0.05)$ (Table $2)$. There were no other significant differences between fatal and non-fatal cases.

Antibiotic resistance rates were high for TMP/SMX (76.2\%), erythromycin $(24.8 \%)$, and penicillin $(22.8 \%)$ (Table 3$)$. The resistance rates for meningeal and non-meningeal isolates for penicillin and ceftriaxone are shown in Figure 1. Penicillin and ceftriaxone non-susceptible strains were significantly more frequent in meningeal, than in non-meningeal isolates $(46.2 \%$ vs. $8.1 \%, P<0.00$; and $23.1 \%$ vs. $4.8 \%, P<0.01$, respectively). Resistance rates (intermediate and high) were higher for children more than 2 years of age than for those younger regarding erythromycin $(40.6 \%$ vs. $17.4 \%, P<0.05)$ and penicillin $(34.4 \%$ vs. $17.4 \%, P=0.05)$, but not significantly different for ceftriaxone $(15.6 \%$ vs. $10.1 \%)$, chloramphenicol $(12.5 \%$ vs. $11.6 \%)$, and TMP/SMX (65.6\% vs. $81.2 \%$ ). Multi-drug resistance (high level resistance by MIC for $\geq$ three antibiotics) was present in $16.8 \%$ of strains.

Ninety nine (98.0\%) strains were available for serotyping (two strains did not grow after storage); 24 different serotypes were found. Serotype distribution is shown in Table 4. The most common serotypes were $14,6 \mathrm{~B}, 19 \mathrm{~F}, 23 \mathrm{~F}$, and 5 which accounted for $69.7 \%$ of all strains and $87.0 \%$ of penicillin non-susceptible strains (Figure 2). The most common serotypes among penicillin non-susceptible isolates were 14, 19F, and 6B. Notably, serotype $19 \mathrm{~A}$ represented only $4.0 \%$ of all isolates, but accounted for $13.0 \%$ of penicillin non-susceptible isolates, although this difference was not statistically significant. The most common sero- types in patients with pneumonia were $1(31.3 \%)$ and $6 \mathrm{~B}(22.9 \%)$; and in patients with meningitis, 14 (23.1\%), 6B (23.1\%) and $19 \mathrm{~F}(17.9 \%)$. The estimated coverage by the 7 -valent conjugated vaccine was $66.7 \%$ in all age groups, $68.6 \%$ in children less than 6 years of age, and $71.6 \%$ in children less than 2 years of age (Table 5).

TABLE 1. General characteristics of 101 children less than 16 years of age hospitalized with invasive pneumococcal disease (IPD) in Lima, Peru, 2006-2008

\begin{tabular}{|c|c|c|}
\hline Characteristic & No. & $\%$ \\
\hline \multicolumn{3}{|l|}{ Gender } \\
\hline Female & 42 & 41.6 \\
\hline Male & 59 & 48.4 \\
\hline Median age (range) & $\begin{array}{c}1.2 \text { years } \\
\text { (1 month-15.8 years) }\end{array}$ & \\
\hline \multicolumn{3}{|l|}{ Age groups (years) } \\
\hline$<2$ & 69 & 68.3 \\
\hline $2-6$ & 19 & 18.8 \\
\hline $6-16$ & 13 & 12.9 \\
\hline \multicolumn{3}{|l|}{ Source of Streptococcus pneumoniae culture } \\
\hline Blood & 59 & 58.4 \\
\hline Cerebral spinal fluid & 29 & 28.7 \\
\hline Pleural fluid & 7 & 6.9 \\
\hline $\begin{array}{l}\text { Other (peritoneal fluid, 2; bronchial alveolar } \\
\text { lavage fluid, 3; and articular fluid, 1) }\end{array}$ & 6 & 5.9 \\
\hline \multicolumn{3}{|l|}{ IPD clinical diagnosis } \\
\hline Pneumonia & 48 & 47.5 \\
\hline Meningitis & 39 & 38.6 \\
\hline Sepsis-bacteremia & 8 & 7.9 \\
\hline Peritonitis & 3 & 3.0 \\
\hline Other (fasceitis, 2; and arthritis, 1) & 3 & 3.0 \\
\hline \multicolumn{3}{|l|}{ Medical condition ${ }^{\mathrm{a}}$} \\
\hline Underlying illness ${ }^{\mathrm{b}}(n=85)$ & 33 & 38.8 \\
\hline Prior hospitalization $(n=85)$ & 41 & 48.2 \\
\hline Received antibiotics in the prior 3 months $(n=78)$ & 31 & 39.7 \\
\hline $\begin{array}{l}\text { Received antibiotics during the current illness } \\
\text { prior to sample collection }(n=90)\end{array}$ & 31 & 34.4 \\
\hline
\end{tabular}

a Clinical data not available in all patients.

${ }^{b}$ Underlying illness: congenital heart disease, 5; malnutrition, 4; asthma/obstructive airway diseases, 4; chronic renal disease, 4; human immunodeficiency virus (HIV), 3; anemia, 3; among others.

TABLE 2. Comparison of 20 fatal versus 71 non-fatal cases of invasive pneumococcal disease in hospitalized children less than 16 years of age in Lima, Peru, 2006-2008

\begin{tabular}{|c|c|c|c|c|}
\hline & \multicolumn{2}{|c|}{ Fatal $(n=20)$} & \multicolumn{2}{|c|}{ Non-fatal $(n=71)$} \\
\hline & No. & $\%$ & No. & $\%$ \\
\hline Age in years, mean \pm standard deviation & $1.8 \pm 2.6$ & & $3.1 \pm 3.8$ & \\
\hline Patients $<2$ years of age & 16 & 80.0 & 36 & $50.7^{a}$ \\
\hline Patients $<6$ years of age & 19 & 95.0 & 52 & 73.2 \\
\hline Days of illness prior to admission, mean $\pm S D$ & $4.9 \pm 4.3$ & & $6.4 \pm 5.2$ & \\
\hline Underlying medical condition & 7 & $35.0^{b}$ & 23 & 32.4 \\
\hline Prior antibiotic use & 6 & 30.0 & 22 & 31.0 \\
\hline Penicillin non-susceptible strains & 4 & 20.0 & 15 & 21.1 \\
\hline Serotypes in PCV-7c & 14 & $70.0^{\mathrm{d}}$ & 43 & 60.6 \\
\hline
\end{tabular}

a $P<0.05$, Yates correction.

${ }^{b}$ Congenital heart disease, 2; malnutrition and anemia, 2; nephrotic syndrome, 1; hepatic cirrhosis, 1; and cleft pa-late, 1.

c PCV-7: heptavalent pneumococcal conjugate vaccine (serotypes 4, 6B, 9V, 14, 18C, 19F, and 23F).

${ }^{d}$ List of all serotypes on fatal cases: $6 \mathrm{~B}, 14$, and 19F (4 strains each); $23 \mathrm{~F}$ ( 2 strains); 3, 5, 6A, 11A, 15A, and 16F (1 strain each). 
TABLE 3. Antimicrobial resistance by minimal inhibitory concentrations (MIC) for Streptococcus pneumoniae in 101 invasive strains in hospitalized children in Lima, Peru, 2006-2008

\begin{tabular}{lcccccccr}
\hline & \multicolumn{2}{c}{ Susceptible } & & \multicolumn{2}{c}{ Intermediate } & & \multicolumn{2}{c}{ Resistant } \\
\cline { 2 - 3 } & No. & $\%$ & & No. & $\%$ & & No. & $\%$ \\
\hline Ceftriaxone & 89 & 88.1 & & 9 & 8.9 & & 3.0 \\
Chloramphenicol & 89 & 88.1 & & - & - & & 12 & 11.9 \\
Penicillin & 78 & 77.2 & & 1 & 1.0 & & 22 & 21.8 \\
Erythromycin & 76 & 75.2 & & 0 & 0 & & 25 & 24.8 \\
TMP/SMXa & 24 & 23.8 & & 13 & 12.9 & & 64 & 63.3 \\
\hline
\end{tabular}

a trimethoprim/sulfamethoxazole.

FIGURE 1. Susceptibility pattern for meningeal and non-meningeal invasive Streptococcus pneumoniae isolates ${ }^{a}$ in hospitalized children less than 16 years of age in Lima, Peru, 2006-2008

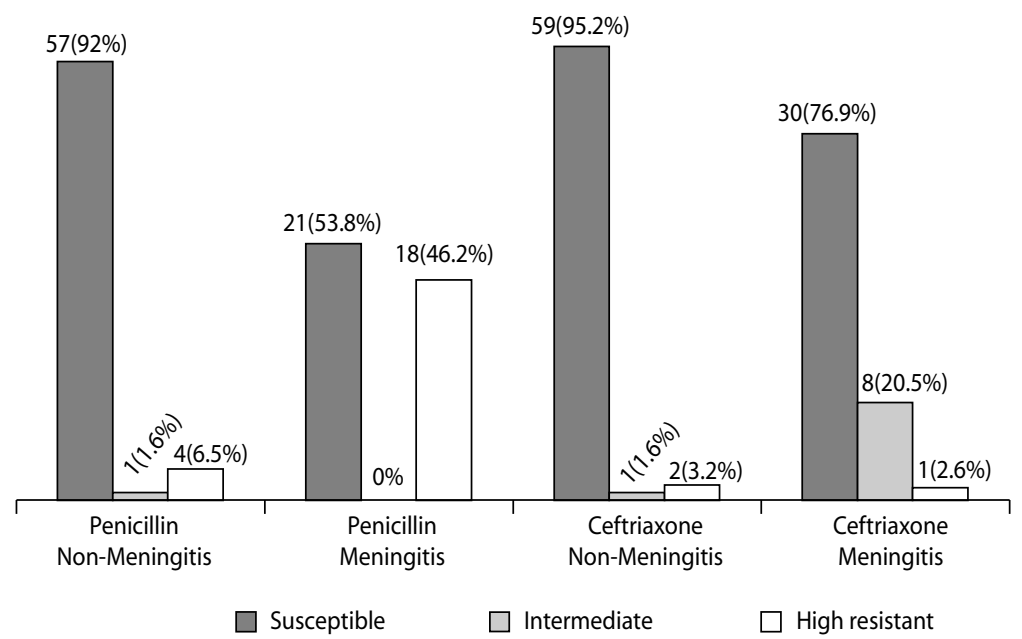

a Percentage of susceptible strains, intermediate resistant, and high resistant by MIC for 62 non-meningeal strains (from patients with infections outside the central nervous system) and 39 meningeal strains (from patient with central nervous system infections)

\section{DISCUSSION}

The estimated mean IPD rate in children less than 24 months of age in Lima was $18.4 / 100000$, which is lower than rates reported from studies done with the same passive surveillance method in other Latin American countries $(16,17)$, and much lower compared to active surveillance studies that also included ambulatory patients $(18,19)$. However, the rate of IPD estimated by this study is based on cases admitted to select hospitals in Lima, and is therefore, an underestimate of the true burden of IPD in Peru. In addition, one of the study's limitations was that the incidence of IPD was calculated based on an estimatethat $75 \%$ of the total population of the Province of Lima receives health care in the hospitals and private clinics that participated in the study. However, this is believed to be a conservative estimate; again, the real burden of IPD is probably much higher. Regardless, this study represents important baseline data for evaluation of the effects after vaccine introduction in Peru.

Mortality from IPD is high in developing countries $(14,16,20,21)$, but varies widely according to clinical presentation, meningitis being the highest. The case fatality rate of IPD in hospitalized children in Lima was $22.0 \%$, high compared to $17 \%$ in a recent, similar study in Chile (16), and 14\% in Costa Rica (20); and much higher than active surveillance studies in Chile (5\%) (18) and Argentina

TABLE 4. Serotype distribution of Streptococcus pneumonia in 99 hospitalized children under 16 years of age with invasive pneumococcal disease in Lima, Peru, 2006-2008

\begin{tabular}{|c|c|c|c|c|c|c|c|c|c|c|}
\hline \multirow[b]{2}{*}{ Serotypes $^{a}$} & \multicolumn{2}{|c|}{$\begin{array}{l}\text { All children } \\
(n=99)\end{array}$} & \multicolumn{2}{|c|}{$\begin{array}{c}\text { Children }<6 \text { years } \\
\qquad(n=86)\end{array}$} & \multicolumn{2}{|c|}{$\begin{array}{c}\text { Children }<2 \text { years } \\
\quad(n=67)\end{array}$} & \multicolumn{2}{|c|}{$\begin{array}{c}\text { Pneumonia } \\
\quad(n=48)\end{array}$} & \multicolumn{2}{|c|}{$\begin{array}{c}\text { Meningitis } \\
(n=39)\end{array}$} \\
\hline & No. & $\%$ & No. & $\%$ & No. & $\%$ & No. & $\%$ & No. & $\%$ \\
\hline 14 & 26 & 26.3 & 23 & 26.7 & 21 & 31.3 & 15 & 31.3 & 9 & 23.1 \\
\hline $6 B$ & 20 & 20.2 & 19 & 22.1 & 16 & 23.9 & 11 & 22.9 & 9 & 23.1 \\
\hline $19 \mathrm{~F}$ & 11 & 11.1 & 9 & 10.5 & 6 & 9.0 & 2 & 4.2 & 7 & 17.9 \\
\hline $23 \mathrm{~F}$ & 6 & 6.1 & 6 & 7.0 & 4 & 6.0 & 3 & 6.3 & 3 & 7.7 \\
\hline 5 & 6 & 6.1 & 6 & 7.0 & 5 & 7.5 & 4 & 8.3 & 1 & 2.6 \\
\hline $6 \mathrm{~A}$ & 4 & 4.0 & 4 & 4.7 & 2 & 3.0 & 3 & 6.3 & 0 & 0.0 \\
\hline $19 A$ & 4 & 4.0 & 4 & 4.7 & 2 & 3.0 & 2 & 4.2 & 2 & 5.1 \\
\hline $9 \mathrm{~V}$ & 1 & 1.0 & 0 & 0.0 & 0 & 0.0 & 1 & 2.1 & 0 & 0.0 \\
\hline $18 \mathrm{C}$ & 1 & 1.0 & 1 & 1.2 & 1 & 1.5 & 0 & 0.0 & 1 & 2.6 \\
\hline 3 & 1 & 1.0 & 1 & 1.2 & 1 & 1.5 & 1 & 2.1 & 0 & 0.0 \\
\hline 4 & 1 & 1.0 & 1 & 1.2 & 0 & 0.0 & 1 & 2.1 & 0 & 0.0 \\
\hline 1 & 0 & 0.0 & 0 & 0.0 & 0 & 0.0 & 0 & 0.0 & 0 & 0.0 \\
\hline $7 F$ & 0 & 0.0 & 0 & 0.0 & 0 & 0.0 & 0 & 0.0 & 0 & 0.0 \\
\hline Other & 18 & $18.2^{b}$ & 12 & 13.7 & 9 & 13.4 & 5 & 10.2 & 7 & 17.9 \\
\hline
\end{tabular}

a List of serotypes present in the 13-valent conjugated pneumococcal vaccine and other serotypes.

${ }^{b}$ Other serotypes: Omni negative (3 strains); 11A, 15A, 24F, 25 (2 strains each); 9N, 12F, 13, 16F, 23A, 34,38 (1 strain each). 
FIGURE 2. Serotypes distribution among all isolates and penicillin non-susceptible Streptococcus pneumoniae isolates ${ }^{a}$ in hospitalized children less than 16 years of age in Lima, Peru, 2006-2008

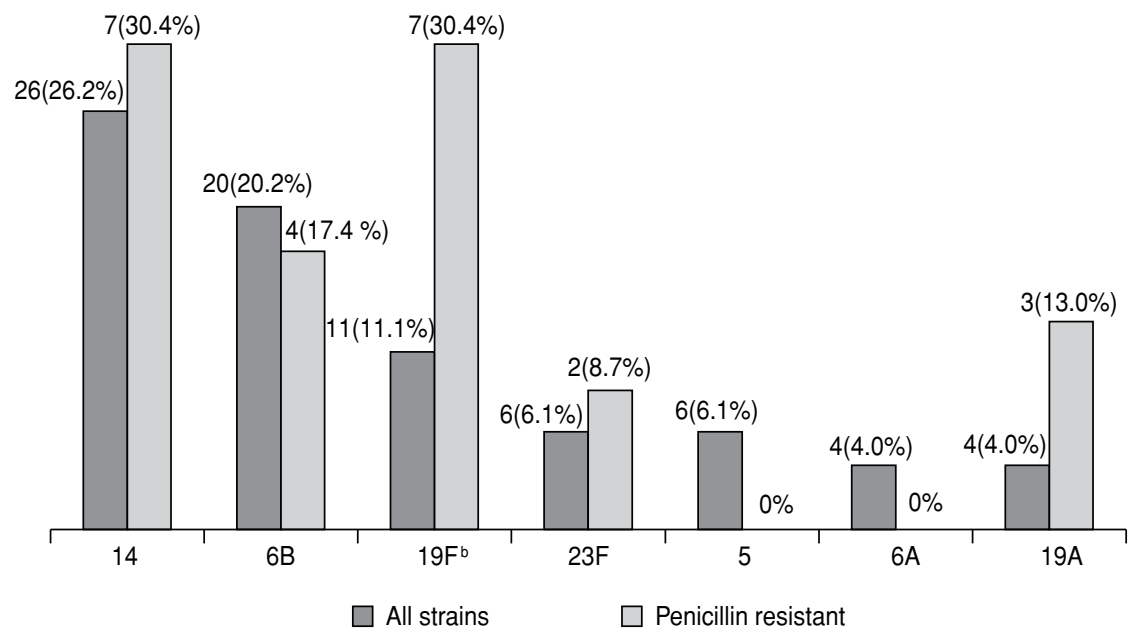

a Percentage of each serotype among all isolates $(n=99)$ and penicillin non-susceptible isolates $(n=23)$.

${ }^{b} P<0.05$ for the comparison between $19 \mathrm{~F}$ penicillin resistant strains and all $19 \mathrm{~F}$ strains $(30.4 \%$ vs. $11.1 \%)$.

(2\%) (19), which have included patients with occult bacteremia with a very low case fatality rate. Meningitis patients had the highest case fatality rate at $32.4 \%$, comparable to that of other developing countries (21-23). Of note is that most fatal IPD cases were in young children and not associated with a higher proportion of penicillin-resistant strains.

Using the new 2008 CLSI/NCCLS breakpoints (15), penicillin resistance was uncommon $(8.1 \%)$ in non-meningeal (pneumonia) isolates and common $(46.2 \%)$ in meningeal isolates. With these resistance levels, penicillin remains the drug of choice for the treatment of nonmeningeal pneumococcal infections (pneumonia) in Peru. However, for empiric treatment of pediatric meningitis, physicians in Lima should use ceftriaxone or other third-generation cephalosporin.
With the current ceftriaxone resistance levels ( $3 \%$ high resistance), adding vancomycin for the initial empiric therapy in all patients with meningitis is debatable.

Nevertheless, antibiotic resistance is increasing in Latin America (24), and continuous monitoring of these trends is important. Previous studies in Peru reported penicillin resistance rates of $15 \%$ (25) and 37\% (26) in nasopharyngeal carriage studies in children, and $27 \%$ in pediatric IPD (27). However, these studies are not comparable, since they were done using previous CLSI/NCCLS breakpoints.

In the present study, the theoretical estimated coverage by the heptavalent conjugated vaccine (PCV-7; serotypes 4, $6 \mathrm{~B}, 9 \mathrm{~V}, 14,18 \mathrm{C}, 19 \mathrm{~F}$, and $23 \mathrm{~F}$ ) was $68.6 \%$ in children less than 6 years of age; $75.6 \%$ with the 10 -valent conjugated vaccine
(PCV-10; serotypes contained in PCV-7, plus serotypes 1, 5, and 7F); and $86.0 \%$ with the 13-valent conjugated vaccine (PCV-13; serotypes contained in PCV-10, plus serotypes 3,6A, and 19A). This concurs with a recent report from the National Institute of Health (Peru) of a passive surveillance study of IPD in children less than 5 years of age. In this national study, the most common serotypes found in 188 strains collected in 2000-2007 were $14(39.4 \%), 6 \mathrm{~B}(9.6 \%), 5$ $(8.5 \%)$, and $19 \mathrm{~F}(4.3 \%)$, with an estimated PCV-7 coverage of 59\% (personal communication, Dr. Sara Morales, Centro Nacional de Salud Pública, Instituto Nacional de Salud, Peru, 2008). The National Immunization Program in Peru started vaccination against pneumococcus in 2009. All infants should be immunized with the pneumococcal conjugate vaccine at 3,5 , and 12 months of age $(2+1$ schedule). Those in high-risk groups receive one additional dose if they are 2-5 years old. In Peru, PCV-7 vaccine is currently the only licensed pneumococcal vaccine.

The estimated coverage of PCV-7 in Latin America varies from 56\%-73\% (16, $19,24,28,29)$. Of note in the present study, serotype 14 was the most predominant-responsible for one-forth of all invasive cases, almost one-third of the pneumonia cases, and one-third of the penicillin non-susceptible strains-just as it is in other Latin American countries. However, there are some variations in the relative frequency of serotypes 1 and 5, which are thought to be occurring more frequently in non-industrialized countries and are serotypes present in the new 10- and 13-valent pneumococcal conjugate vaccines. In the present study, these two serotypes represented only $6 \%$ of all strains, compared to $14 \%$ in Chile (16), $18 \%$ in Argentina (19), and $22 \%$ in

TABLE 5. Estimated coverage with pneumococcal conjugate vaccines in children in Lima, Peru, based on the serotype distribution of invasive pneumococcal strains in 99 hospitalized children less than 16 years of age in Lima, Peru, 2006-2008

\begin{tabular}{|c|c|c|c|c|c|c|c|c|c|c|}
\hline \multirow[b]{2}{*}{ Vaccine coverage } & \multicolumn{2}{|c|}{$\begin{array}{l}\text { All children } \\
\quad(n=99)\end{array}$} & \multicolumn{2}{|c|}{$\begin{array}{c}\text { Children }<6 \text { years } \\
\qquad(n=86)\end{array}$} & \multicolumn{2}{|c|}{$\begin{array}{c}\text { Children }<2 \text { years } \\
\quad(n=67)\end{array}$} & \multicolumn{2}{|c|}{$\begin{array}{l}\text { Pneumonia } \\
\quad(n=48)\end{array}$} & \multicolumn{2}{|c|}{$\begin{array}{c}\text { Meningitis } \\
(n=39)\end{array}$} \\
\hline & No. & $\%$ & No. & $\%$ & No. & $\%$ & No. & $\%$ & No. & $\%$ \\
\hline PCV-7a & 66 & 66.7 & 59 & 68.6 & 48 & 71.6 & 33 & 68.8 & 29 & 74.4 \\
\hline PCV-10 & 72 & 72.7 & 65 & 75.6 & 53 & 79.1 & 37 & 77.1 & 30 & 76.9 \\
\hline$P C V-13^{c}$ & 81 & 81.8 & 74 & 86.0 & 58 & 86.6 & 43 & 89.6 & 32 & 82.1 \\
\hline
\end{tabular}

a PCV-7, currently licensed 7-valent pneumococcal conjugate vaccine (serotypes 4, 6B, 9V, 14, 18C, 19F, and 23F).

b PCV-10, 10-valent pneumococcal conjugate vaccine (serotypes contained in PCV-7 plus serotypes 1, 5, and 7F).

c PCV-13, 13-valent pneumococcal conjugate vaccine (serotypes contained in PCV-10 plus serotypes 3, 6A, and 19A). 
Brazil (28). However, serotypes 1 and 5 are known to have cyclical fluctuations of incidence (16); therefore, serotype distribution should be continuously monitored over time in Peru, especially now that PCV-7 is being introduced in the general population.

Serotype distribution varies geographically. This variation is thought to be attributable to different blood-culture rates and practices, which substantially affect the perceived coverage of multivalent pneumococcal-conjugate vaccines (12). Although the ranking of individual pneumococcal serotypes that cause serious disease varies from country to country, it is known that the 7-13 serotypes found in the conjugate pneumococcal vaccines are expected to prevent $50 \%-$ $90 \%$ of all pediatric disease worldwide $(14,29)$. In view of the global disease burden, WHO has recommended that inclusion of pneumococcal conjugate vaccine in national immunization programs be made a priority in countries with high infant mortality (30).

Acknowledgements. The authors wish to thank the directors and staff of the microbiology laboratories and the pediatricians from all the hospitals and clinics that participated in the study: Humberto Guerra and Lida Mejía (Instituto de Medicina Tropical Alexander von Humboldt, Universidad Peruana Cayetano Heredia); Lilian Patiño and Rito Zerpa, (Instituto Nacional de Salud del Niño); Máximo Camiña (Hospital de Emergencias Pediátricas); Roger Hernández and Elena Tapia (Hospital Nacional Cayetano Heredia); Elba Linares (Hospital Edgardo Rebagliati); Manuel Leiva and Francisco Mestanza (Hospital Nacional Docente Madre-Niño San Bartolomé); José María Guevara (Hospital Daniel A. Carrión); Mónica Castañeda and Rafael Ramírez (Hospital Guillermo Almanera); Rafael Ortiz, Martha Urbina, and Raúl Molina (Hospital María Auxiliadora); José Campos and Gladys Patiño (Hospital Hipólito Unanue); Debbie Miyasato and Jorge Velásquez (Hospital Arzobispo Loayza); Luis Cam (Hospital Sabogal); Carmen Risco (Clínica Maison de Santé); Cecilia Barreda (Clínica San Pablo); Ana Prada (Blufstein lab); Alejandro Colichon and Mardonia Nicasio (Med Lab); Luciano Poletti (Anglo Lab);
Carlos Roe (Roe Lab); Claudia Gianolli (Suiza Lab). Special appreciation goes to Sara Morales and Victor Suarez (Instituto Nacional de Salud, Peru) for their help with serotyping of some strains.

This study was funded by a research grant from Laboratorios Wyeth S.A. (Lima, Peru). Theresa Ochoa is supported by the PHS-FIC grant 1K01TW007405. The content is solely the responsibility of the authors and does not necessarily represent the official views of the Fogarty International Center (Bethesda, Maryland, United States) or the National Institutes of Health (Bethesda, Maryland, United States).

Potential conflict of interest. Wyeth Pharmaceuticals (newly acquired by Pfizer Incorporated, New York, United States) is licensed to market the PCV-7 vaccine in Peru. Theresa Ochoa, María Castillo, Wilda Silva, and Eduardo Chaparro have served as consultants to Wyeth Pharmaceuticals; and Theresa Ochoa has received research grants from Wyeth as well. There are no potential conflicts of interest for the other authors.

\section{REFERENCES}

1. World Health Organization. Pneumococcal vaccines. Wkly Epidemiol Rec. 2003;78(14): 110-19.

2. Organización Panamericana de la Salud. Estimando la mortalidad por enfermedades prevenibles mediante vacunación en las Américas. Bol Inmunización. 2006;28(3):5-6.

3. Castanheira M, Gales AC, Mendes RE, Jones $\mathrm{RN}$, Sader HS. Antimicrobial susceptibility of Streptococcus pneumoniae in Latin America: results from five years of the SENTRY Antimicrobial Surveillance Program. Clin Microbiol Infect. 2004;10(7):645-51.

4. Hortal M, Lovgren M, de la Hoz F, Agudelo CI, Brandileone MC, Camou T, et al. Antibiotic resistance in Streptococcus pneumoniae in six Latin American countries: 1993-1999 surveillance. Microb Drug Resist. 2001;7(4): 391-401.

5. Whitney CG, Farley MM, Hadler J, Harrison LH, Bennett NM, Lynfield R, et al. Decline in invasive pneumococcal disease after the introduction of protein-polysaccharide conjugate vaccine. N Engl J Med. 2003;348(18): 1737-46.

6. Klugman KP, Madhi SA, Huebner RE, Kohberger R, Mbelle N, and Pierce N. A trial of a 9-valent pneumococcal conjugate vaccine in children with and those without HIV infection. N Engl J Med. 2003;349(14):1341-8.
7. Black $S$, Shinefield $H$, Baxter $R$, Austrian $R$, Bracken L, Hansen J, Lewis E, Fireman B. Post licensure surveillance for pneumococcal invasive disease after use of heptavalent pneumococcal conjugate vaccine in Northern California Kaiser Permanente. Pediatr Infect Dis J. 2004;23(6):485-9.

8. Cutts FT, Zaman SMA, Enwere G, Levine OS, Okoko JB, Oluwalana C, et al. Efficacy of nine-valent pneumococcal conjugate vaccine against pneumonia and invasive pneumococcal disease in The Gambia: randomized, double-blind, placebo-controlled trial. Lancet. 2005;365(9465):1139-46.

9. Kyaw MH, Lynfield $R$, Schaffner $W$, Craig AS, Hadler J, Reingold A, et al. Effect of introduction of the pneumococcal conjugate vaccine on drug-resistant Streptococcus pneumoniae. N Engl J Med. 2006;354(14):1455-63.

10. Hausdorff WP, Bryant J, Paradiso PR, Siber GR. Which pneumococcal serogroups cause the most invasive disease: implications for conjugate vaccine formulation and use, part I. Clin Infect Dis. 2000;30(1):100-21.

11. Hausdorff WP, Bryant J, Kloek C, Paradiso PR, Siber GR. The contribution of specific pneumococcal serogroups to different disease manifestations: implications for conjugate vaccine formulation and use, part II. Clin Infect Dis. 2000;30(1):122-40.
12. Hausdorff WP, Siber G, Paradiso PR. Geographical differences in invasive pneumo coccal disease rates and serotype frequency in young children. Lancet. 2001;357(9260): 950-2.

13. Hausdorff WP, Feikin DR, and Klugman KP. Epidemiological differences among pneumococcal serotypes. Lancet Infect Dis. 2005;5(2): 83-93.

14. Levine OS, O'Brien KL, Knoll M, Adegbola RA, Black S, Cherian T, et al. Pneumococcal vaccination in developing countries. Lancet. 2006;367(9526):1880-2.

15. Clinical and Laboratory Standards Institute (CLSI). Performance standards for antimicrobial susceptibility testing. 18th informational supplement. CLSI: Wayne PA; 2008. M100S18.

16. Lagos R, Muñoz A, San Martin O, Maldonado A, Hormazabal JC, Blackwelder WC, et al. Age- and serotype-specific pediatric invasive pneumococcal disease: insights form systematic surveillance in Santiago, Chile, 19942007. J Infect Dis. 2008;198(12):1809-17.

17. Lagos R, Muñoz A, Valenzuela MT, Heitmann I, Levine MM. Population-based surveillance for hospitalized and ambulatory pediatric invasive pneumococcal disease in Santiago, Chile. Pediatr Infect Dis J. 2002;21(12): 1115-23. 
18. Abarca VK, Vergara FR, Tassara PE, Ibañez WI, García BC, Potin SM. Invasive pneumococcal disease and consolidated pneumonia in infants: one year of surveillance in three Chilean health care centers. Rev Chilena Infectol. 2008;25(2):97-103.

19. Tregnaghi $M$, Ceballos $A$, Rüttimann $R$, Ussher J, Tregnaghi $\mathrm{P}$, Peeters $\mathrm{P}$, et al. Active epidemiologic surveillance of pneumonia and invasive pneumococcal disease in ambulatory and hospitalized infants in Cordoba, Argentina. Pediatr Infect Dis J. 2006;25(4): $370-2$.

20. Ulloa-Gutierrez R, Avila-Aguero ML, Herrera ML, Herrera JF, Arguedas A. Invasive pneumococcal disease in Costa Rican children: a seven year survey. Pediatr Infect Dis J. 2003; 22(12):1069-74.

21. Campbell JD, Kotloff KL, Sow SO, Tapia M, Keita MM, Keita T, et al. Invasive pneumococcal infections among hospitalized children in Bamako, Mali. Pediatr Infect Dis J. 2004;23(7): 642-9.

22. Chong CY, Koh-Cheng T, Yee-Hui M, Nancy TW. Invasive pneumococcal disease in Singapore children. Vaccine. 2008;26(27-28): 3427-31.
23. Roca A, Sigauque B, Quintó L, Mandomando I, Vallès X, Espasa M, et al. Invasive pneumococcal disease in children $<5$ years of age in rural Mozambique. Trop Med Int Health. 2006;11(9):1422-31.

24. Agudelo CI, Castañeda E, Corso A, Regueira $\mathrm{M}$, Brandileone MC, Brandão AP, et al. Resistance to non-beta-lactam antibiotics in the clinical isolates of Streptococcus pneumoniae of children in Latin America. SIREVA II, 20002005. Rev Panam Salud Publica. 2009;25(4): 305-13.

25. Cullotta AR, Kalter HD, Delgado J, Gilman RH, Facklan RR, Velapatino B, et al. Antimicrobial susceptibilities and serotype distribution of Streptococcus pneumoniae isolates from a low socioeconomic area in Lima, Peru. Clin Diagn Lab Immunol. 2002;9(6):1328-31.

26. Ochoa TJ, Rupa R, Guerra H, Hernandez H, Chaparro E, Tamariz J, et al. Penicillin resistance and serotypes/serogroups of Streptococcus pneumoniae in nasopharyngeal carrier children younger than 2 years in Lima, Peru. Diagn Microbiol Infect Dis. 2005;52(1):59-64.

27. Morales S, Diaz S, Gonzalez D, Huapaya B. Susceptibilidad antimicrobiana del Streptococcus pneumoniae determinando la concen- tración inhibitoria mínima, 1999. Rev Peru Med Exp Salud Publica. 2001;18(1-2):35-7.

28. Berezin EN, Cardenuto MD, Ferreira LL, Otsuka M, Guerra ML, Brandileone MC. Distribution of Streptococcus pneumoniae serotypes in nasopharyngeal carriage and in invasive neumococcal disease in Sao Paulo, Brazil. Pediatr Infect Dis J. 2007;26(7):643-5.

29. Valenzuela MT, O'Loughlin R, De La Hoz F, Gomez E, Constenla D, Sinha A, et al. The burden of pneumococcal disease among Latin American and Caribbean children: review of the evidence. Rev Panam Salud Publica. 2009;25(3):270-9.

30. World Health Organization. Pneumococcal conjugate vaccine for childhood immunization [WHO position paper]. Wkly Epidemiol Rec. 2007;82(12):93-104.

Manuscript received on 16 December 2009. Revised version accepted for publication on 6 July 2010.

RESUMEN Objetivo. Determinar la epidemiología de la enfermedad neumocócica invasora y la sensibilidad a los antibióticos y la distribución de los serotipos de S. pneumoniae en pacientes pediátricos en Lima, Perú.

\section{Enfermedades neumocócicas invasoras en niños hospitalizados en Lima, Perú}

Palabras clave
Métodos. Estudio multicéntrico de vigilancia pasiva durante dos años, entre mayo del 2006 y abril del 2008, en 11 hospitales públicos y 5 consultorios privados de Lima, en pacientes menores de 16 años con cultivos de sitios estériles positivos para S. pneumoniae. Se determinó la sensibilidad a los antibióticos mediante Etest ${ }^{\circledR}$ (AB Biodisk, Solna, Suiza). Se serotipificaron las cepas mediante la reacción de Quellung.

Resultados. En total, se estudiaron 101 episodios de enfermedad neumocócica invasora, $68,3 \%$ de ellos en niños menores de 24 meses, con los siguientes diagnósticos: neumonía $(47,5 \%)$, meningitis $(38,6 \%)$ y septicemia $(7,9 \%)$. La tasa de letalidad general fue de $22,0 \%$ y la tasa de letalidad por meningitis de $32,4 \%$. Si bien $80,0 \%$ de los casos mortales ocurrió en menores de 24 meses, solo 50,7\% de los casos no mortales $(P<0,05)$ ocurrió en este grupo de edad. Las tasas de resistencia fueron elevadas para trimetoprima-sulfametoxazol $(76,2 \%)$, eritromicina $(24,8 \%)$ y penicilina $(22,8 \%)$. Los serotipos más comunes, $14,6 \mathrm{~B}, 19 \mathrm{~F}, 23 \mathrm{~F}$ y 5 , representaron $69,7 \%$ de todas las cepas, y $87,0 \%$ de las cepas no sensibles a la penicilina.

Conclusiones. La enfermedad neumocócica invasora en niños hospitalizados en Lima se asocia con altos niveles de resistencia a los antimicrobianos y una tasa de letalidad elevada, especialmente en niños pequeños. Estos datos iniciales serán útiles para evaluar los efectos de la introducción de las vacunas.

Streptococcus pneumoniae; infecciones neumocócicas; niño hospitalizado; cuidado del niño; vacunas neumocócicas; Perú. 